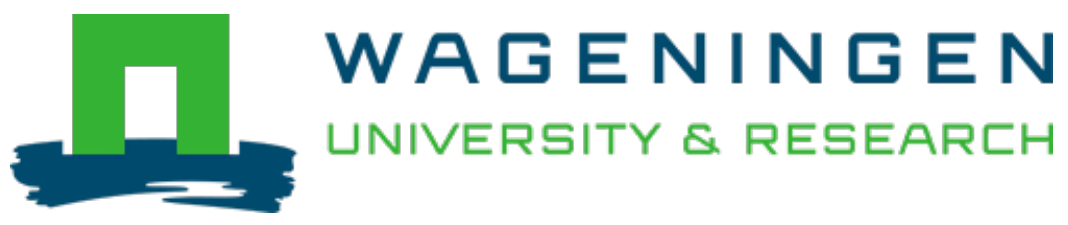

\title{
Projected climate change causes loss and redistribution of neutral genetic diversity in a model metapopulation of a medium-good disperser
}

\author{
Ecography \\ Cobben, M.M.P.; Verboom, J.; Opdam, P.F.M.; Hoekstra, R.F.; Jochem, R. et al \\ https://doi.org/10.1111/j.1600-0587.2011.06713.x
}

This article is made publicly available in the institutional repository of Wageningen University and Research, under the terms of article $25 \mathrm{fa}$ of the Dutch Copyright Act, also known as the Amendment Taverne. This has been done with explicit consent by the author.

Article 25 fa states that the author of a short scientific work funded either wholly or partially by Dutch public funds is entitled to make that work publicly available for no consideration following a reasonable period of time after the work was first published, provided that clear reference is made to the source of the first publication of the work.

This publication is distributed under The Association of Universities in the Netherlands (VSNU) 'Article $25 \mathrm{fa}$ implementation' project. In this project research outputs of researchers employed by Dutch Universities that comply with the legal requirements of Article $25 \mathrm{fa}$ of the Dutch Copyright Act are distributed online and free of cost or other barriers in institutional repositories. Research outputs are distributed six months after their first online publication in the original published version and with proper attribution to the source of the original publication.

You are permitted to download and use the publication for personal purposes. All rights remain with the author(s) and / or copyright owner(s) of this work. Any use of the publication or parts of it other than authorised under article $25 \mathrm{fa}$ of the Dutch Copyright act is prohibited. Wageningen University \& Research and the author(s) of this publication shall not be held responsible or liable for any damages resulting from your (re)use of this publication.

For questions regarding the public availability of this article please contact openscience.library@,wur.nl 


\title{
Projected climate change causes loss and redistribution of genetic diversity in a model metapopulation of a medium-good disperser
}

\author{
M. M. P. Cobben, J. Verboom, P. F. M. Opdam, R. F. Hoekstra, R. Jochem, P. Arens and M. J. M. \\ Smulders
}

M. M. P. Cobben (marleen.cobben@wur.nl) P. Arens and M. J. M. Smulders, Plant Research International, Wageningen UR, PO Box 16, NL6700 AA Wageningen, the Netherlands, and Alterra, Wageningen UR, PO Box 47, NL-6700 AA Wageningen, the Netherlands. - MMPC, J. Verboom, P. F. M. Opdam and R. Jochem, Alterra, Wageningen UR, PO Box 47, NL-6700 AA Wageningen, the Netherlands, and Land Use Planning Group, Wageningen UR, PO Box 47, NL-6700 AA Wageningen, the Netherlands. - R. F. Hoekstra, Laboratory of Genetics, Wageningen UR, PO Box 309, NL-6700 AH Wageningen, the Netherlands.

\begin{abstract}
Climate change causes species ranges to shift geographically as individuals colonise new suitable temperature zones or fail to reproduce where climate conditions fall below tolerance levels. Little is known about the potential loss of genetic diversity in such dynamic ranges. We investigated the level and distribution of neutral genetic diversity in shifting metapopulations during three scenarios of temperature increase projected for this century and at various degrees of weather variability. We used an individual-based and spatially explicit metapopulation model in which temperature zones were simulated to move across a fragmented landscape following different climate change scenarios. Although the connectivity between habitat patches allowed the species, modelled after the middle spotted woodpecker Dendrocopos medius, to move along with the shifting temperature range, existing neutral genetic diversity was lost under all three temperature increase scenarios. This was independent of the loss of individuals. The explanation for this effect is that only a part of the original genetic variation moved into the newly colonised habitat. Under increased weather variability the number of individuals and the number of alleles per locus were persistently lower. However, the pattern of changes in allele distributions under temperature zone shifts was the same under all weather variability levels. Genetic differentiation between populations had a tendency to increase at metapopulation range margins, but decreased again when population sizes increased in time. Increased weather variability led to increased variation around the mean genetic differentiation across the metapopulation. Our results illustrate the usefulness of more realistic models for studying the effects of climate change on metapopulations. They indicate that biodiversity monitoring indices based on species occurrence and abundance are not a good proxy for the trend in the level of genetic diversity. Further, the results underline the importance of conserving areas where species have existed for a long time as modern refugia for genetic diversity.
\end{abstract}

Adoption of the Convention on Biological Diversity at the 1992 Earth Summit in Rio de Janeiro has led to a worldwide commitment to sustain the diversity of life on Earth. This has resulted in widely used biodiversity monitoring tools and conservation programmes. One of the threats to biodiversity are current climatic changes (IUCN in Foden et al. 2008), reflected in increased temperature and increased weather variability (IPCC 2007). Increased temperature may cause a shift of species ranges when species follow suitable temperature zones (Parmesan and Yohe 2003, Root et al. 2003, Parmesan 2006). Relatively rapid climate change may cause extinctions of species that are not able to track suitable conditions due to limited dispersal capacities (Schippers et al. 2011). On top of this, movement of individuals and hence also range shifts can be hampered by fragmentation of habitat (Warren et al. 2001, Travis 2003, Opdam and Wascher 2004, Vos et al. 2008).

Additionally, range shifts have population genetic consequences. If expansion at the leading edge of the range occurs through a sequence of founder effects, this results in a reduction of genetic diversity in the newly colonized habitat (Nei et al. 1975, Hewitt 1996, Austerlitz et al. 1997, Hewitt and Nichols 2005, Neve et al. 2009). Therefore, after a period of range expansion, genetic diversity in a species range is decreasing from the rear edge to the leading edge (Hewitt 1996, McInerny et al. 2009). This has been shown in a strategic model of the fate of mutations during population expansion into new habitat (McInerny et al. 2009). It has also been shown to be the general pattern in 
several groups of species as a consequence of range expansion across central and northwestern Europe after the last ice age (Hewitt 1996).

Range shifts are different from range expansions since there is also a range retraction at the trailing edge to consider. McInerny et al. (2009) showed in a modelling approach that survival of neutral mutations at the trailing edge is reduced as a result of decreasing habitat suitability.

The predicted increased weather variability may increase population extinction rates (Leigh 1981, Lande 1993, Saether et al. 1998, Verboom et al. 2010) and thus lead to an increase in number of founder events under range shifts through enhanced extinction-colonisation cycles. This would have consequences for the level of genetic diversity in newly colonised regions. Besides, this effect may be enhanced by decreased habitat size and increased habitat isolation resulting from habitat fragmentation.

From the above we conclude that the currently predicted climate change may affect the genetic diversity of species (Hewitt and Nichols 2005, McInerny et al. 2009). However, projections of future climate, including both temperature and weather variability increase, have not yet been incorporated in studies modelling the effects on species' genetic diversity. Existing models have thus so far also taken a more strategic approach, using non-specific, simplified assumptions about species' demography and genetics. Besides, spatial irregularity in habitat configurations has not been incorporated into these strategic studies. See e.g. McInerny et al. (2009), who included range shifts but limited their study to clonal haploid reproduction and a landscape grid with population sizes 0 or 1 . Edmonds et al. (2004) studied range expansion only. They allowed population growth but limited themselves to clonal haploid reproduction and a landscape grid. Klopfstein et al. (2006) used a landscape grid and haploid individuals under range expansion as did Travis et al. (2007). Bruggeman et al. (2010) did study the effects of habitat loss and fragmentation on genetic variation in a complex model based on realistic ecological and population genetic data in irregular landscapes. Yet this study was not focused on changing species' ranges.

In this paper we explore how range shifts induced by the predicted climate change will affect the level and distribution of neutral genetic diversity in a species range. We chose a more complex approach in an attempt to realistically model a specific species, the middle spotted woodpecker Dendrocopos medius. This species has a medium dispersal capacity, with an average yearly dispersal distance in the same order of magnitude as the yearly temperature zone shift. We used an individual-based and spatially explicit metapopulation model in which temperature zones were simulated to move across a fragmented landscape following different scenarios for predicted climate change (Hadley Centre 2003). Since we are interested in the demographic effects of climate change on genetic diversity, we investigated neutral genetic diversity only to not confuse genetic signatures of range shifts with signatures of selection (Excoffier and Ray 2008, Excoffier et al. 2009). We expected that in the newly colonised areas, allelic diversity will decrease and genetic differentiation between populations will increase (Eckert et al. 2008). Further, we expected that both trends may be correlated with temperature increase and increased weather variability.
To investigate these expectations we specifically asked how: 1) predicted temperature increase, and 2) predicted temperature increase combined with increased weather variability affect the level and distribution of neutral genetic diversity in the species range in time.

Building on both the above mentioned studies into population genetics and on frequently used climate-envelope models (Settele et al. 2008), we believe our modelling approach is a further step towards more realistic speciesspecific assessments of climate change effects (Scoble and Lowe 2010).

\section{Methods}

For this study we used METAPHOR, a simulation model for metapopulation demography (Verboom et al. 2001, Vos et al. 2001). The model has been extended to allow for temperature zone shifts and weather variability by Schippers et al. (2011). Here a new extension provided each individual in this study with a genome of 10 unlinked diploid genes (representing 1 locus at each of 10 different chromosomes). Population genetics in our model was the result of population demography. There was no reciprocal effect of genetics on demography, thus all genes were neutral. Reproduction, dispersal and survival were based on population density and habitat quality. Habitat quality was controlled by time and location specific temperature. As such we simulated the effect of stochastic temperature zone shifts on neutral genetic diversity. For detailed information see Supplementary material Appendix 1: detailed model description and Appendix 2: genetic make-up and protocol. Table 1 gives an overview of all species, gene and climate parameters used.

The landscape we used in the model had dimensions of $15 \mathrm{~km}$ from east to west by $2000 \mathrm{~km}$ from north to south. The east and west side were merged to create a cylindric landscape. The landscape contained 3000 circular habitat patches of 50 ha each, so consisted of a total of $5 \%$ habitat. Patches were placed in random positions in the landscape, yet only allowed if they were at a minimum distance of $150 \mathrm{~m}$ from existing patches. Five landscape variants with different habitat positions were randomly generated and each simulated parameter setting was repeated twice in each landscape variant.

We modelled a woodland bird, parameterised as the middle spotted woodpecker Dendrocopus medius. Parameters were based on biological information (Pettersson 1985a, b, Hagemeijer and Blair 1997, Pasinelli 2000, Kosenko and Kaigorodova 2001, Michalek and Winkler 2001, Kosinski et al. 2004, Kosinski and Ksit 2006) and on the interpretation by Schippers et al. (2011) (Table 1). The model distinguished two sexes and two lifestages. Recruitment, dispersal and survival were all dependent of population density and habitat quality. From their origin patch individuals could disperse in every direction, along a straight line. Connectivity to other patches was determined by destination patch radius and by distance from original to destination patch. The maximum dispersal distance was 15 $\mathrm{km}$, so habitat patches that were separated by more than this distance were not connected at all. Our model did not allow dispersers to ignore a nearer patch, so more distant 
Table 1. Model parameters used. Species and climate parameters are those used by Schippers et al. (2011). Parameter names link this table to the functions in Supplementary material Appendix 1: detailed model description.

\begin{tabular}{|c|c|c|c|}
\hline Parameter description & Value & Unit & Parameter name \\
\hline $\begin{array}{l}\text { Landscape parameters } \\
\text { number of patches } \\
\text { patch area } \\
\text { patch carrying capacity }\end{array}$ & $\begin{array}{l}3000 \\
50 \\
20\end{array}$ & $\begin{array}{l}\text { ha } \\
\text { individuals }\end{array}$ & \\
\hline $\begin{array}{l}\text { Species parameters } \\
\text { Recruitment } \\
\text { area per reproductive unit } \\
\text { recruitment at density }=0 \text { and quality }=1 \\
\text { recruitment at density }=1 \text { and quality }=1 \\
\text { recruitment at density }=0 \text { and quality }=0\end{array}$ & $\begin{array}{l}5 \\
2.4 \\
1.8 \\
0\end{array}$ & $\begin{array}{l}\text { ha } \\
\text { juveniles/female } \\
\text { juveniles/female } \\
\text { juveniles/female }\end{array}$ & $\begin{array}{l}\mathrm{N}_{\mathrm{O} \_P D O H Q 1} \\
\mathrm{~N}_{\mathrm{O} \_P D 1 H Q 1} \\
\mathrm{~N}_{\mathrm{O} \_P D O H Q 0}\end{array}$ \\
\hline $\begin{array}{l}\text { Dispersal } \\
\text { maximum dispersal distance } \\
\text { maximum detection distance } \\
\text { juvenile dispersal probability } \\
\text { at density }=0 \text { and quality }=1 \\
\text { at density }=1 \text { and quality }=1 \\
\text { at density }=0 \text { and quality }=0 \\
\text { adult dispersal probability } \\
\text { at density }=0 \text { and quality }=1 \\
\text { at density }=1 \text { and quality }=1 \\
\text { at density }=0 \text { and quality }=0\end{array}$ & $\begin{array}{l}15 \\
150 \\
\\
0 \\
0.6 \\
1 \\
\\
0 \\
0.1 \\
0.5\end{array}$ & $\begin{array}{l}\mathrm{km} \\
\mathrm{m} \\
\mathrm{yr}^{-1} \\
\mathrm{yr}^{-1} \\
\mathrm{yr}^{-1} \\
\mathrm{yr}^{-1} \\
\mathrm{yr}^{-1} \\
\mathrm{yr}^{-1}\end{array}$ & $\begin{array}{l}\mathrm{I} \\
\mathrm{P}_{\mathrm{D} \_ \text {PDOHQ1 }} \\
\mathrm{P}_{\mathrm{D} \_ \text {PD1HQ1 }} \\
\mathrm{P}_{\mathrm{D} \_ \text {PDOHQO }} \\
\mathrm{P}_{\mathrm{D} \_ \text {PDOHQ1 }} \\
\mathrm{P}_{\mathrm{D} \text { DPD1HQ1 }} \\
\mathrm{P}_{\mathrm{D} \_ \text {PDOHQ0 }}\end{array}$ \\
\hline $\begin{array}{l}\text { Survival } \\
\text { juvenile survival probability } \\
\text { adult survival probability at quality }=1 \\
\text { adult survival probability at quality }=0\end{array}$ & $\begin{array}{l}0.8 \\
0.55\end{array}$ & $\begin{array}{l}\mathrm{yr}^{-1} \\
\mathrm{yr}^{-1}\end{array}$ & 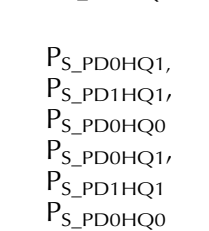 \\
\hline $\begin{array}{l}\text { Genetic parameters } \\
\text { allele range at initialisation } \\
\text { allele range after mutation } \\
\text { mutation rate }\end{array}$ & $\begin{array}{l}1-20 \\
21-50 \\
10^{-4}\end{array}$ & generation $^{-1}$ & \\
\hline $\begin{array}{l}\text { Climate parameters } \\
\text { temperature isocline speed } \\
\text { weather variability } \\
\text { temperature tolerance } \\
\text { initial temperature optimum location }\end{array}$ & $\begin{array}{l}2,4,8 \\
0,140,280 \\
800 \\
400\end{array}$ & $\begin{array}{l}{\mathrm{km} \mathrm{yr}^{-1}}^{\mathrm{km}} \\
\mathrm{km} \\
\mathrm{km} \text { from the south edge }\end{array}$ & $\begin{array}{l}\mathrm{T} \\
\sigma_{\mathrm{d}} \\
\mathrm{H} \\
\mathrm{Y}_{\mathrm{opt}, 0}\end{array}$ \\
\hline $\begin{array}{l}\text { Model run parameters } \\
\text { burn-in } \\
\text { investigated time points after burn-in }\end{array}$ & $\begin{array}{l}3000 \\
0,25,50,75 \\
100,125,150 \\
200,250,300 \\
400,500,600\end{array}$ & $\begin{array}{l}\mathrm{yr} \\
\mathrm{yr}\end{array}$ & \\
\hline
\end{tabular}

patches are located in the shadow of the nearer patch. An individual may arrive in a patch with a population size larger than carrying capacity twice per dispersal event, and was then allowed to disperse again. Should it fail to reach a habitable patch within three dispersal rounds, it would die.

The climate optimum was shifting northwards according to the temperature increase scenario used (see below and Table 1). The weather variability was simulated by the standard deviation of the average temperature (see below and Table 1). Climate suitability was translated to a habitat patch quality ranging from 0 to 1 , based on distance from the climate optimum and on the half value parameter used, following a Gaussian curve (Schippers et al. 2011). We used three temperature isocline speed scenarios, based on work by the Hadley Centre (2003). The first scenario was a temperature increase of $1^{\circ} \mathrm{C}$ from year 2000 to 2100 . For as far as we know now, this is an unrealistic prediction for the coming century but we incorporated it as an absolute minimal change to compare with the more likely scenarios of a 2 and $4^{\circ} \mathrm{C}$ temperature increase by 2100 (Hadley Centre 2003). When translating these scenarios to temperature isocline speeds we assumed that the simulated metapopulation was situated along the European Atlantic coast. Unaffected by mountain ranges it has the temperature gradient of $0.0042{ }^{\circ} \mathrm{C} \mathrm{km}^{-1}$ (Schippers et al. 2011). The three scenarios were therefore equivalent to isocline speeds of respectively 2, 4 and $8 \mathrm{~km} \mathrm{yr}^{-1}$. Weather variability was modelled as the standard deviation of the average temperature, which currently is $0.59^{\circ} \mathrm{C}$ and was thus translated to $140 \mathrm{~km}$ (Schippers et al. 2011). To assess the effect of increased weather variability we also applied levels of 280 and $0 \mathrm{~km}$.

At initialisation of the model, all habitat patches were filled with 10 adult individuals, equaling half the carrying capacity. Each individual was randomly given 2 alleles per locus for 10 different, unlinked loci. The initial alleles had 
allele numbers ranging from 1 to 20. We allowed for mutations at a rate of $10^{-4}$ generation $^{-1}$, the mutation rate of medium-sized (20 repeats) microsatellites per haplotype per generation (Whittaker et al. 2003). Mutations generated new alleles with a random number between 21 and 50 (for more detailed information see Supplementary material Appendix 2: genetic make-up and protocol). All alleles were neutral and thus had no effect on individual performance.

After initialisation we allowed a generous burn-in of 3000 generations to obtain the equilibrium situation (for more detailed information see Supplementary material Appendix 2: genetic make-up and protocol). During these 3000 generations, the model was run with temperature zone speed equaling zero but the simulated weather variability was already used. In the remainder of the paper, time 0 was set after the burn-in.

Schippers et al. (2011) found that under the parameter settings used, this species responded differently to our three different temperature zone shift scenarios. This allowed us to study the genetic signatures of three demographically different range shifts: no decline in population numbers, slow decline and fast decline.

\section{Simulation experiments}

With our first experiment we investigated how predicted temperature increase affected the level and distribution of neutral genetic diversity in the species range in time. In this experiment the temperature isoclines were simulated to move northward for $600 \mathrm{yr}$ according to the three climate scenario speeds and one control speed of zero $\mathrm{km} \mathrm{yr}^{-1}$. The weather variability was maintained at the estimated current value of $140 \mathrm{~km}$ throughout the entire experiment.

With our second experiment we investigated the combined effect of both predicted temperature increase and increased weather variability on the level and distribution of neutral genetic diversity in the species range in time. In this experiment the temperature isoclines were again simulated to move northward for $600 \mathrm{yr}$ according to the three climate scenario speeds and one control speed of $0 \mathrm{~km}$ $\mathrm{yr}^{-1}$, but now for each of these scenarios the weather variability had values of 0,140 or $280 \mathrm{~km}$.

\section{Analysis}

For both experiments we were interested in the changes in level and distribution of neutral genetic diversity in time and space. We calculated two measures of genetic diversity: the average actual number of alleles per locus (A) and the average effective number of alleles per locus $\left(A_{e}\right)$, with the latter following the equation (Frankham et al. 2005):

$A_{e}=\frac{1}{\sum_{\mathrm{i}} \mathrm{p}_{\mathrm{i}}^{2}}$

where $\mathrm{p}_{\mathrm{i}}$ denotes the frequency of allele $\mathrm{i}$ in the population. Field studies take samples of the entire population and are thus confined to using $A_{e}$. Differences between $A$ and $A_{e}$ provide information about low-frequency alleles, such as new mutations. We stored and analysed data for 13 time slices consisting of the years: $0,25,50,75,100,125,150$, 200, 250, 300, 400, 500, and 600. To investigate the distribution of genetic diversity we cut the landscape in ranges of $50 \mathrm{~km}$ and calculated $\mathrm{A}$ and $\mathrm{A}_{\mathrm{e}}$ both for the whole metapopulation and for the combined populations in each $50 \mathrm{~km}$ range. To study the distribution of genetic diversity within these $50 \mathrm{~km}$ ranges, we furthermore calculated the genetic differentiation between populations $\left(\mathrm{F}_{\mathrm{ST}}\right)$ for the combined populations in each range. Lastly, to compare with and correct for population size, we calculated the average number of individuals $(\mathrm{N})$. For structuring the data and calculating the allele frequencies and $\mathrm{F}_{\mathrm{ST}}$ values we used Genepop 4.0 (Rousset 2008). For studying trends in numbers of individuals and alleles, we averaged these per parameter setting. For individuals we averaged over the two runs of the five landscape variants, for alleles we also averaged over the 10 loci. For both experiments we calculated confidence intervals to show variation between different runs.

\section{Results}

\section{The effects of predicted temperature increase}

Level of neutral genetic diversity

The first experiment showed that under the temperature isocline speed of 0 and $2 \mathrm{~km} \mathrm{yr}^{-1}$, the number of individuals in the metapopulation remained more or less the same over a period of $600 \mathrm{yr}$ (Fig. 1a). Under speeds of 4 and $8 \mathrm{~km} \mathrm{yr}^{-1}$, individual numbers linearly decreased after a small lag phase, which ended in the metapopulation going extinct under the conditions simulated in these scenarios. The decrease in number of individuals was correlated with temperature isocline speed, i.e. the faster the temperature optimum moved, the faster the number of individuals decreased and the sooner extinction occurred.

The average number of alleles per locus showed a somewhat different result (Fig. 1b). The number of alleles decreased in time in all climatic change scenarios, including the $2 \mathrm{~km} \mathrm{yr}^{-1}$ temperature isocline shift scenario in which the number of individuals did not decrease. The decline of the number of alleles was faster with increased temperature isocline shift speed. The average effective number of alleles per locus also decreased in time in all scenarios at a rate negatively correlated to the speed of the temperature isocline shift (Fig. 1c). However, the rates of decline were higher than those of the average number of alleles under the same scenario. The loss of alleles could in part be the result of the decreasing population size (but notice the $2 \mathrm{~km} \mathrm{yr}^{-1}$ scenario). To correct for this potential effect we selected a subset of 100 individuals for all scenarios and time slices. Also in such a sample of constant population size, alleles were lost in all scenarios (Fig. 1d). The effective numbers of alleles showed the same pattern (not shown).

\section{Spatial distribution of neutral genetic diversity}

Figure 2 displays for one temperature increase scenario (the $2 \mathrm{~km} \mathrm{yr}^{-1}$ temperature isocline shift) the spatial distributions of individuals, alleles and effective number of alleles 

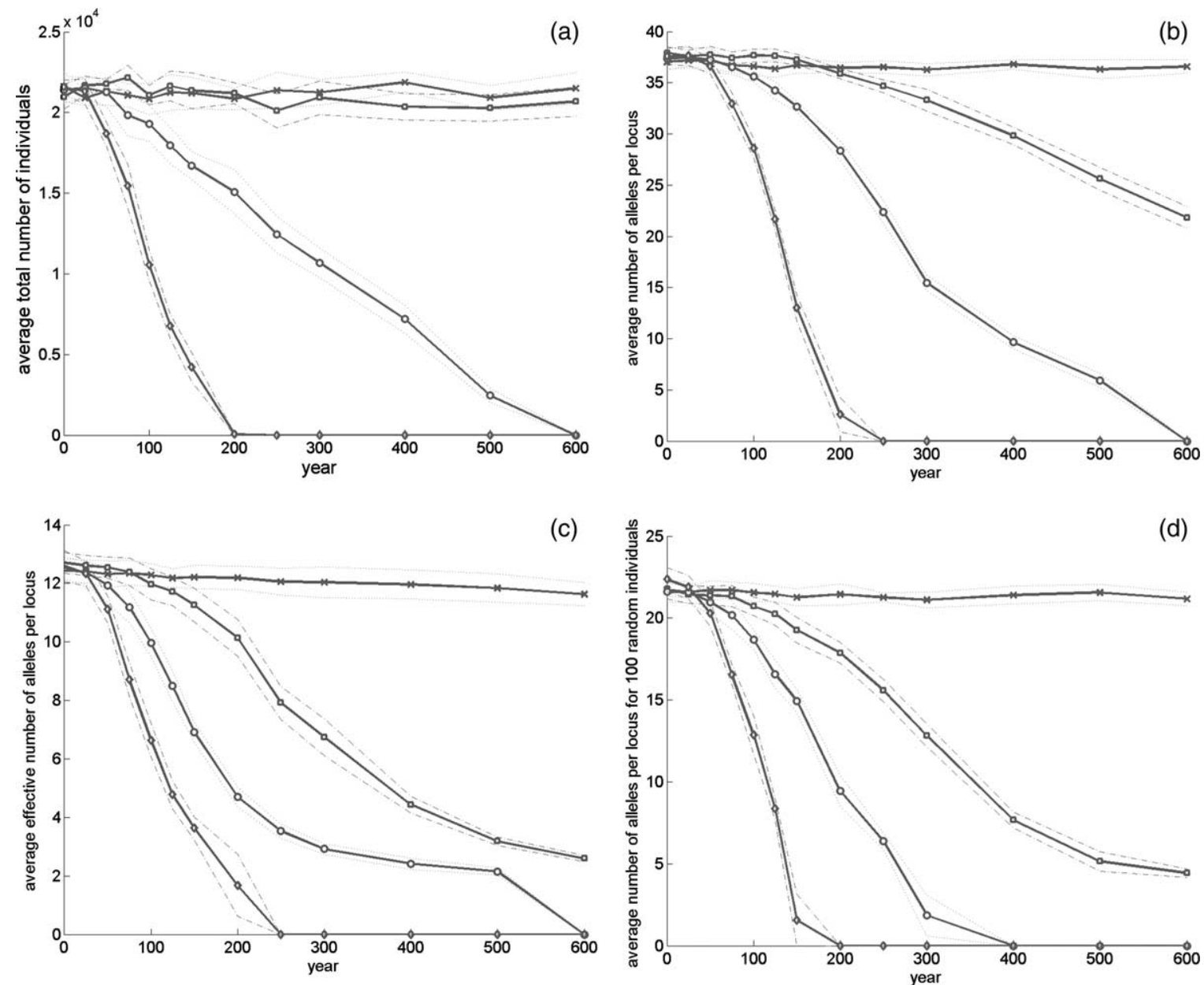

Figure 1. The effects of four temperature isocline speeds $0(-\mathrm{x}-), 2(-\square-), 4\left(-\bigcirc_{-}\right)$, and $8\left(-\searrow_{-}\right) \mathrm{km} \mathrm{yr}^{-1}$ on average number of individuals (a), average number of alleles per locus (b), average effective number of alleles per locus (c), and average number of alleles per locus for 100 random individuals (d). Dotted lines (.. and .-) give 95\% confidence intervals. (b-d): data are the average of 10 loci. Weather variability was $140 \mathrm{~km}$.

during the movement of the climate optimum northwards. The peak of the distribution of individuals more or less followed the temperature optimum during its movement northward, but the individuals that occupied the newly colonized area north of the original habitat carried only a small subset of the alleles. Most of the alleles present in populations that used to be in the centre of the metapopulation prior to temperature change, remained there. This led to a highly skewed distribution of the - effective number of alleles in the metapopulation from year 250 onwards, with populations towards the trailing edge of the metapopulation being significantly more genetically diverse. As the climate optimum continued to move northward, these populations started to decrease in size and finally went extinct, leading to loss of alleles.

Figure 3 shows the distribution of the $\mathrm{F}_{\mathrm{ST}}$ values of all 10 simulated runs within each $50 \mathrm{~km}$ range for the $2 \mathrm{~km} \mathrm{yr}^{-1}$ temperature isocline shift. Most $\mathrm{F}_{\mathrm{ST}}$ values were very small, but there was a tendency towards higher values near the range edges, where the average numbers of individuals were lower (compare Fig. 2 with Fig. 3). The $\mathrm{F}_{\mathrm{ST}}$ values in scenarios of 4 and $8 \mathrm{~km} \mathrm{yr}^{-1}$ temperature isocline shift showed similar patterns (not shown).

\section{The interaction of predicted temperature increase and increased weather variability}

\section{Level of neutral genetic diversity}

We ran our temperature change scenarios at twice the standard level of random weather variability, so with a standard deviation (SD) of the temperature optimum of 280 $\mathrm{km}$, and for comparison also without any random weather variability between years $(S D=0)$. The results indicated two different effects of an increase of weather variability. Firstly, the number of individuals (Supplementary material Fig. A31a in Appendix 3: extra figures) and the actual (Fig. 4a) and effective numbers of alleles (Supplementary material Fig. A3-1b in Appendix 3: extra figures) were smaller under larger weather variation across the whole range. This is already visible at $\mathrm{t}=0$, as the weather variability was already simulated during the burn-in phase. Corrected for the decrease in population size (Fig. 4b), we see that increased weather variability led to a small loss of neutral genetic diversity independent of population size. Secondly, the variation in the number of individuals between replicate runs was larger under increased weather variability (Supplementary material Fig. A3-1a in Appendix 3: extra figures). 
(a)

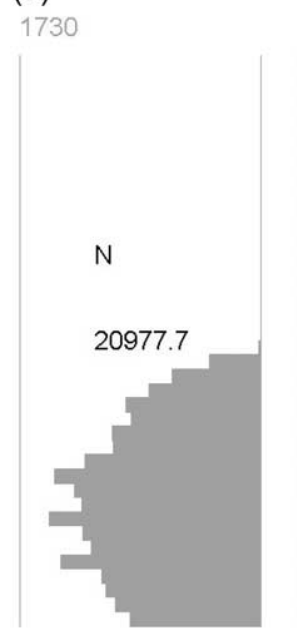

(c)
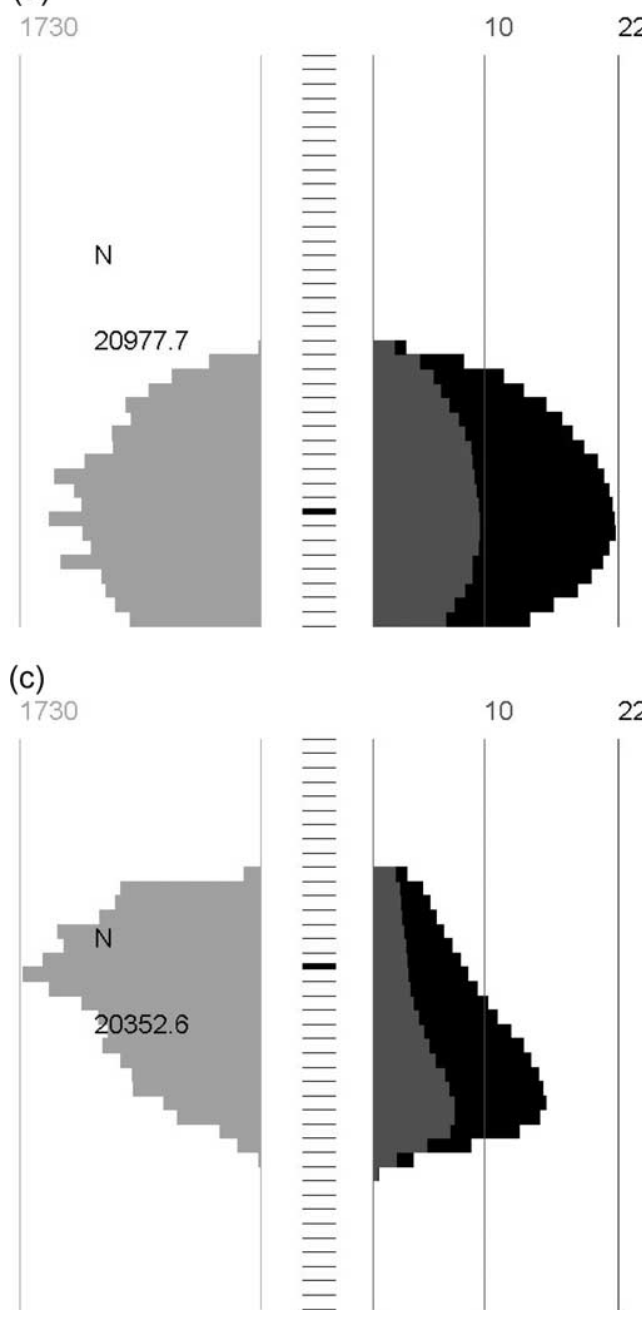

(b)

22

37.9

1730

Ae

12.7

year

0
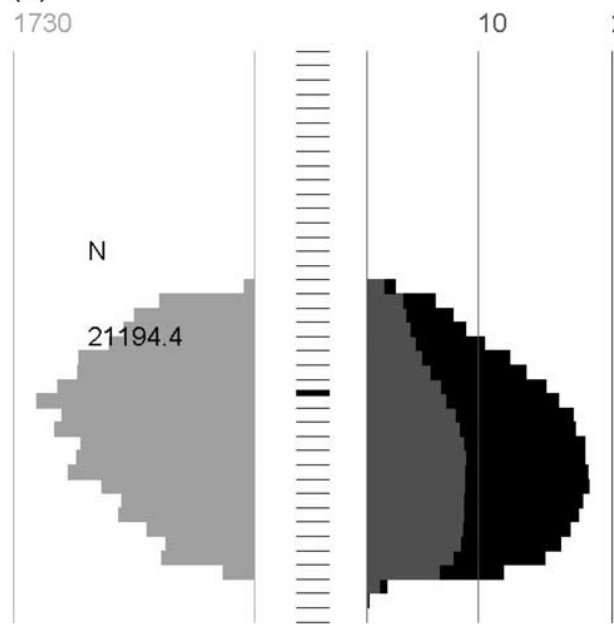

22

A

$\mathrm{Ae}$

year

200

(d)
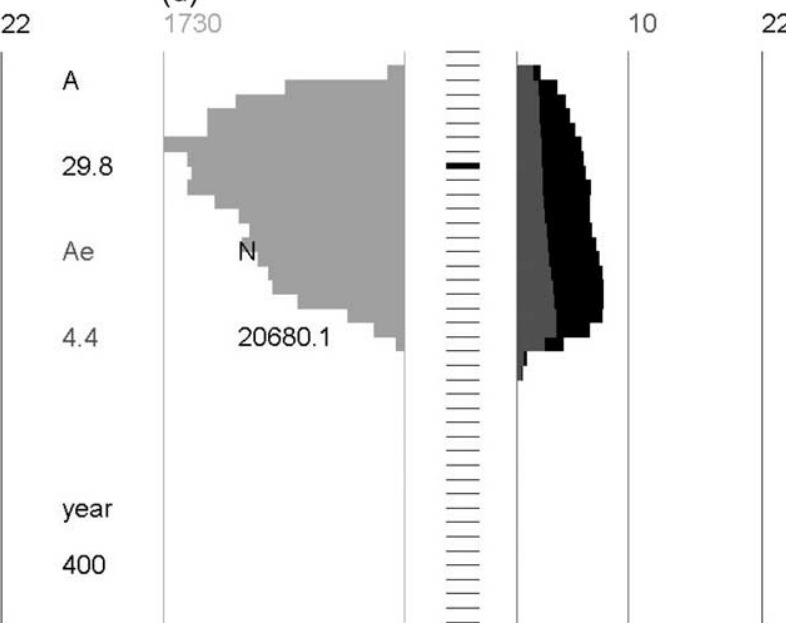

22
A

$\mathrm{Ae}$

year

600

Figure 2. The spatial distribution of individuals, alleles and effective number of alleles during the movement of the habitat optimum northwards at $2 \mathrm{~km} \mathrm{yr}^{-1}$, in 4 time steps: year 0 (a), 200 (b), 400 (c) and 600 (d). For assessing the number of individuals and their neutral genetic diversity the populations were grouped in $50 \mathrm{~km}$ ranges, displayed as the horizontal lines in the figure center. The bold horizontal line indicates the year-specific location of the temperature optimum. The bars display the average number of individuals per 50 $\mathrm{km}$ range (light gray, to the left), and the number of alleles (in black, to the right) and effective number of alleles (in dark gray, to the right). In each time slice (year indicated at the bottom right) also the total number of individuals $(\mathrm{N})$, alleles $(\mathrm{A})$ and effective number of alleles $\left(A_{e}\right)$ for the whole metapopulation are indicated. The vertical lines serve as scales and specifically indicate the found maximum numbers of individuals and alleles in any $50 \mathrm{~km}$ range across all time slices. Weather variability was $140 \mathrm{~km}$.

Increasing variation is indicated by increasingly wide confidence intervals with increasing weather variability.

\section{Spatial distribution of neutral genetic diversity}

The increase in weather variability did not affect the initial metapopulation range (compare Fig. 5a and b as typical examples of what we see under all scenarios), nor did it affect the retraction of the rear end of the species range (compare Fig. $5 \mathrm{c}$ with d). However, the peak distribution of individuals was flattened under large weather variability, which is the main reason why the metapopulation contained fewer individuals under larger weather variability. Apparently, a large yearly variation prevented the species from fully occupying the habitat under optimal conditions, leading to increased habitat occupancy under limited weather variability. Under temperature increase, the overall pattern of individual and allele distributions under range shifts was however not affected by increased weather variability, despite the effect on absolute numbers (compare Fig. 5a with c, and b with d).

In Fig. 6 we show the distribution of the $\mathrm{F}_{\mathrm{ST}}$ values of all 10 simulated runs within each $50 \mathrm{~km}$ range for the scenario of $4 \mathrm{~km} \mathrm{yr}^{-1}$ temperature isocline shift under weather variabilities of zero and $280 \mathrm{~km}$. Range edges again showed a tendency towards higher $\mathrm{F}_{\mathrm{ST}}$ values. Besides this effect, there was more variation in the $\mathrm{F}_{\mathrm{ST}}$ values throughout the entire metapopulation under high weather variability. This last effect was independent of local population sizes.

\section{Discussion}

The purpose of this study was to investigate how range shifts induced by the predicted climate change may affect 
(a)

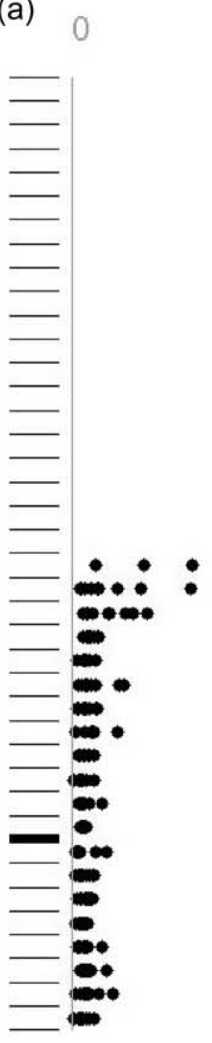

(c)

0

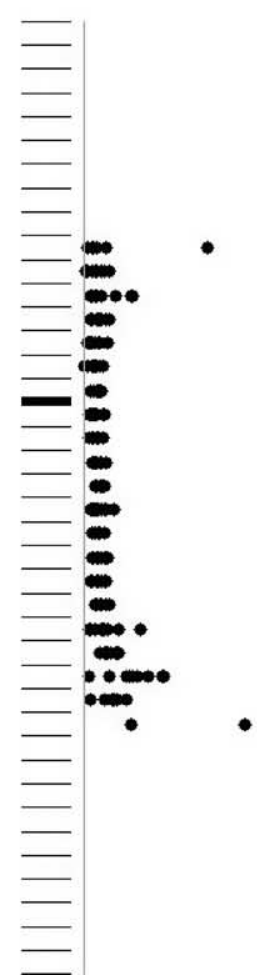

year 0

0.2

(b)

year

200

0.2

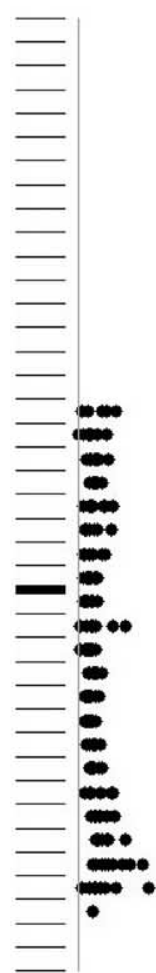

(d)

0.2

year $\quad 400$

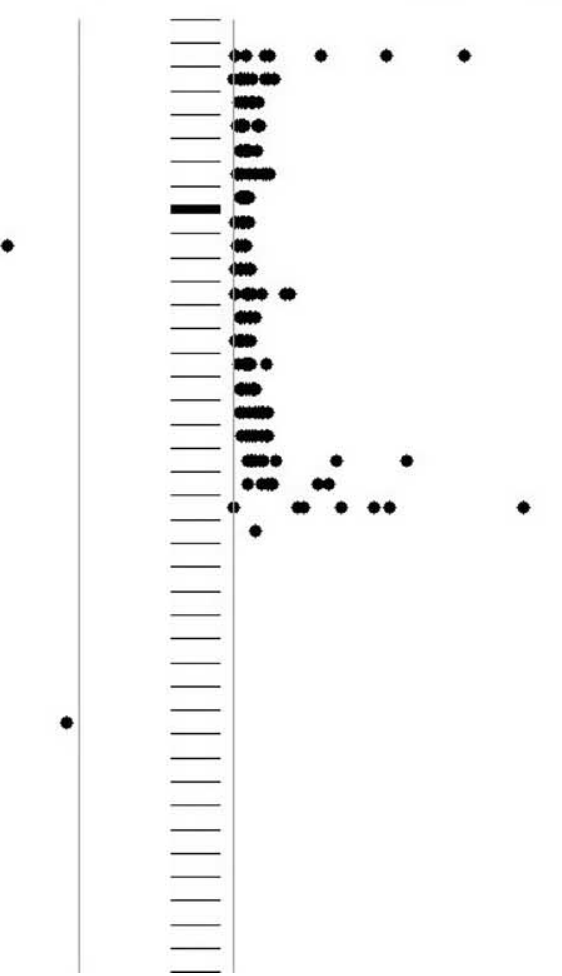

0.2

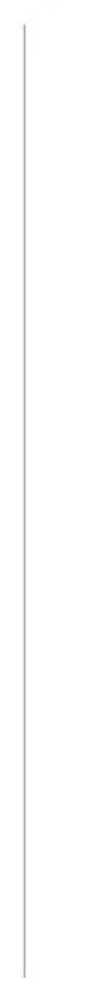

Figure 3. All $\mathrm{F}_{\mathrm{ST}}$ values in each $50 \mathrm{~km}$ range (displayed as the horizontal lines) during the movement of the temperature optimum (bold horizontal line) northwards at $2 \mathrm{~km} \mathrm{yr}^{-1}$. Missing values (i.e. $<10 \mathrm{~F}_{\mathrm{ST}}$ values noted per range) are the result of simulations leading to 0 individuals in this range. Weather variability was $140 \mathrm{~km}$. 
(a)
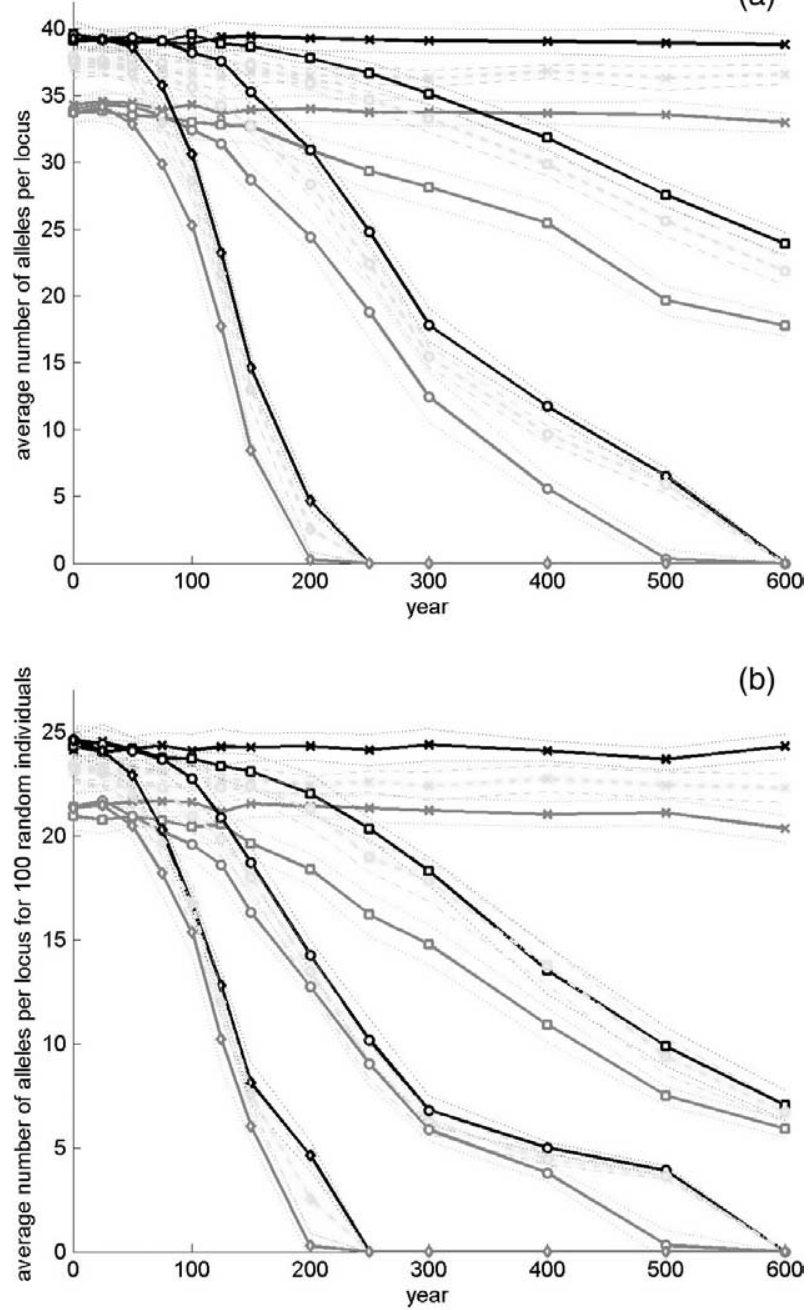

Figure 4. Average number of alleles per locus per year (a) and average number of alleles per locus for 100 random individuals per year (b) for all combined temperature isocline speeds $0(-\mathrm{x}-)$, $2(-\square-), 4\left(-\bigcirc_{-}\right)$, and $\left.8(-\rangle_{-}\right) \mathrm{km} \mathrm{yr}^{-1}$, and random weather variabilities of 0 (black), 140 (light gray) and 280 (dark gray) km. Dotted lines indicate confidence intervals.

the level and distribution of neutral genetic diversity in a species range. For this we modelled both demography and genetics of a species with medium dispersal capacity in a metapopulation setting under climate-induced range shifts. Range shifts induced by the predicted temperature increase led to loss of neutral genetic diversity in the metapopulation, even if the metapopulation size remained unaffected. When comparing the effects of temperature increase and weather variability in our model, temperature increase appeared to be the dominant factor in affecting population size, the level of neutral genetic diversity and the spatial distributions of both. The genetic differentiation between populations increased due to increased weather variability and in range margins, but this effect was limited.

Effects of range expansions and range shifts on population genetics have been studied before (Hewitt 1996, Edmonds et al. 2004, Klopfstein et al. 2006, Travis et al. 2007, Excoffier et al. 2009, McInerny et al. 2009). With this study we have attempted to make a species-specific assessment of the effect of climate change on neutral genetic diversity. For this we incorporated, in contrast to similar modelling studies, species-specific life history traits, diploid inheritance of alleles, temperature variability and predicted increase of temperature, and spatial irregularity through random habitat configurations. Thus we could study simultaneously how metapopulation demography was affected by climate change and in turn affected the metapopulation genetics for a specific species.

The results of this study provide insight into how projections of current climate change may affect metapopulation-wide neutral genetic diversity in dispersers of medium quality. Besides, the results illustrate the usefulness of more realistic models for studying these complex issues. Further, we hope this study may provide additional food for thought in assessments of currently used monitoring tools and conservation programmes.

\section{The effects of temperature increase induced range shifts on neutral genetic diversity}

Neutral genetic diversity was lost under all three temperature increase scenarios, and this loss also occurred when the number of individuals did not decrease during range shift, which was only the case in the $1^{\circ} \mathrm{C}$ temperature increase per century scenario. The loss of neutral genetic diversity was visible both as a decrease of the actual number of alleles (the sum of common and (very) rare alleles) and of the effective number of alleles (which corrects for differences in allele frequencies). It was also present when we corrected for differences in population size. Schippers et al. (2011) concluded that metapopulation survival can be enhanced by limiting future temperature increase. We subscribe to this conclusion and extend it to the preservation of neutral genetic diversity. However, in our model all range shifts led to loss of neutral genetic diversity, suggesting that some loss of genetic diversity may be inevitable under a broad range of scenarios of climate change.

Neutral genetic diversity was lost as a result of a series of effects. The genetic diversity near the ranges of the metapopulation was lower than in the centre as a result of lower habitat suitability, and thus lower population density (Eckert et al. 2008). Besides, the genetic diversity of individuals dispersing into newly suitable areas was only a part of the gene pool present near the original leading range. As a result, populations in newly colonised habitats at the leading edge of the metapopulation only contained a fraction of the neutral genetic diversity that was present in the centre of the metapopulation. Earlier studies (Edmonds et al. 2004, Klopfstein et al. 2006, Excoffier and Ray 2008) have shown low-frequency alleles at the leading range edge to reach high frequencies in newly colonised areas, at the cost of the presence and abundance of other alleles. This is called the surfing effect. Travis et al. (2007) in a study on adaptive mutations, showed that this effect is strong enough to even increase the frequencies of deleterious mutations in new populations. In other words, selection may not undo the demographic effect of serial founder events, as was predicted by Nei (1975). Here we show that the same mechanism leads to the loss of existing neutral alleles in a metapopulation. The total number of alleles was lower in 
(a)

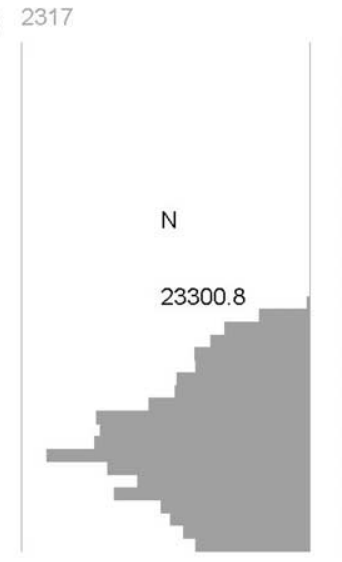

(b)

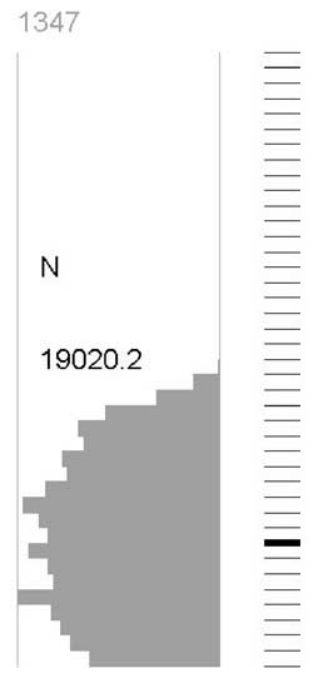

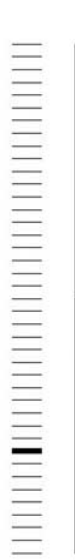
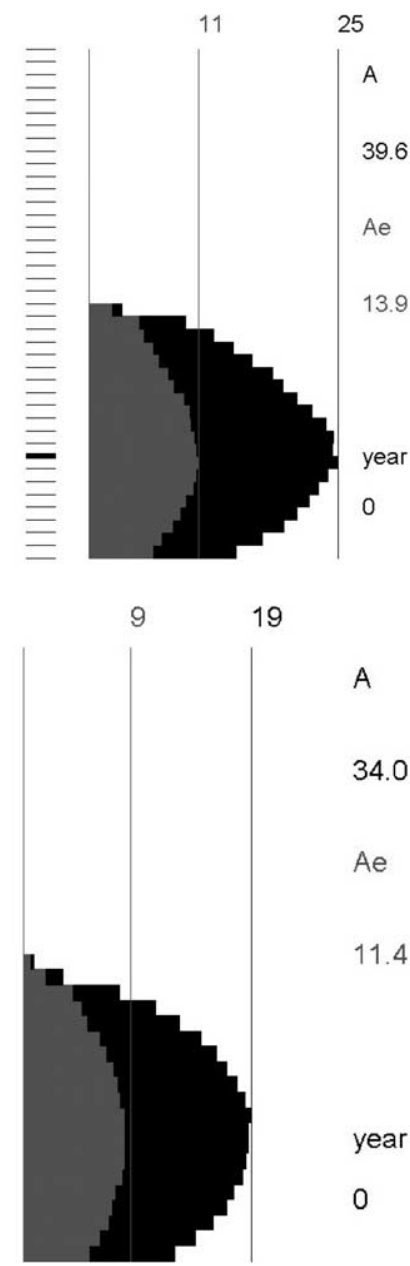

(c)
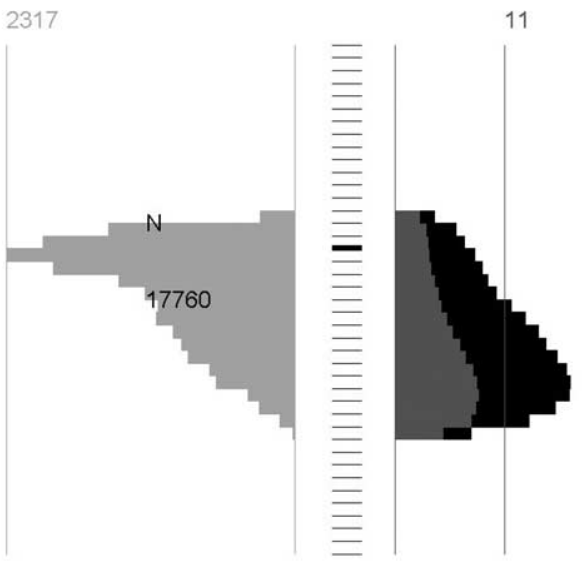

(d)
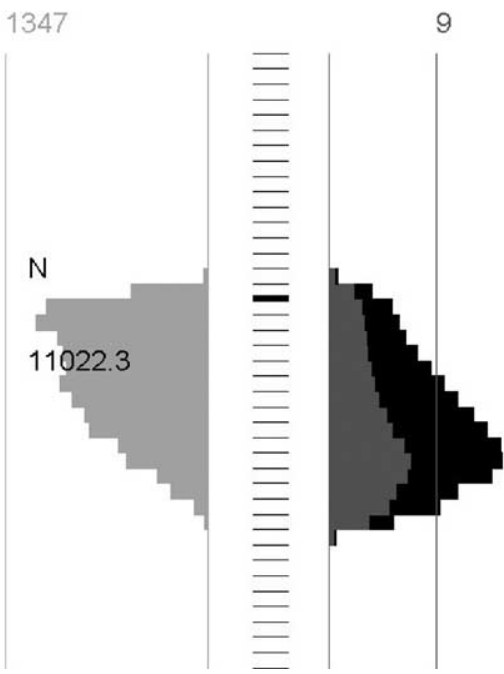

19

A

$\mathrm{Ae}$

year

200

Figure 5. Overview of differences in spatial distribution of individuals, number of alleles per locus and effective number of alleles per locus in each $50 \mathrm{~km}$ range (displayed as the horizontal lines in the figure center) at $4 \mathrm{~km} \mathrm{yr}^{-1}$ optimum temperature (bold horizontal line) speed for random weather variabilities of $0(a, c)$ and $280(b, d) \mathrm{km}$ in years $0(\mathrm{a}, \mathrm{b})$ and $200(\mathrm{c}, \mathrm{d})$. The bars display the average number of individuals per $50 \mathrm{~km}$ range (light gray, to the left), and the number of alleles (in black, to the right) and effective number of alleles (in dark gray, to the right). In each time slice (year indicated at the bottom right) also the total number of individuals $(\mathrm{N})$, alleles (A) and effective number of alleles $\left(A_{e}\right)$ for the whole metapopulation are indicated. The vertical lines serve as scales and specifically indicate the found maximum numbers of individuals and alleles in any $50 \mathrm{~km}$ range in all time slices of a single averaged parameter set.

newly colonized areas, indicating that not all alleles entered the new habitat. The effective number of alleles declined faster than the actual number of alleles, most clearly in the 1 and $2^{\circ} \mathrm{C}$ temperature increase per century scenarios, indicating that a few alleles increased in frequency at the expense of the abundances of all other alleles. This result is consistent with previous work on mutations (Edmonds et al. 2004, Klopfstein et al. 2006, Travis et al. 2007) which showed that a low initial frequency does not prevent an allele from surfing.

As the metapopulation continued to move in time, the consequence of this surfing behaviour was that the patches with the highest level of allelic diversity, which were originally at the centre of the metapopulation, became situated in the lagging edge in the southern range. This has been shown before in a strategic model of the fate of neutral markers (McInerny et al. 2009). On a different scale of space and time, it resembles the distribution of neutral genetic diversity in diverse groups of species which have undergone range expansion across central and northwestern
Europe after the last ice age (Hewitt 1996, Besold et al. 2008). Hampe and Petit (2005) have pointed out the relative importance of rear-edge populations as long term stores of species' genetic diversity. In our model, the location of the maximum genetic diversity was more or less stationary in space, but the metapopulation as a whole shifted northward. This was not the consequence of an inability of alleles to move within the metapopulation but of a slow effective rate of movement. Boileau et al. (1992) already showed persistent founder effects in natural populations. They concluded from theory and computer simulations that allele frequencies established during colonisation by few individuals are resistant to decay by allele exchange, when this population grows rapidly after founding.

Finally, when southern populations started to go extinct once temperature became too high in that region, neutral genetic diversity was lost. This process leading to allele loss concurs with theory (Nei et al. 1975), strategic modelling studies (Boileau et al. 1992, McInerny et al. 2009) and emperical findings (Boileau et al. 1992, Hewitt 1996). 

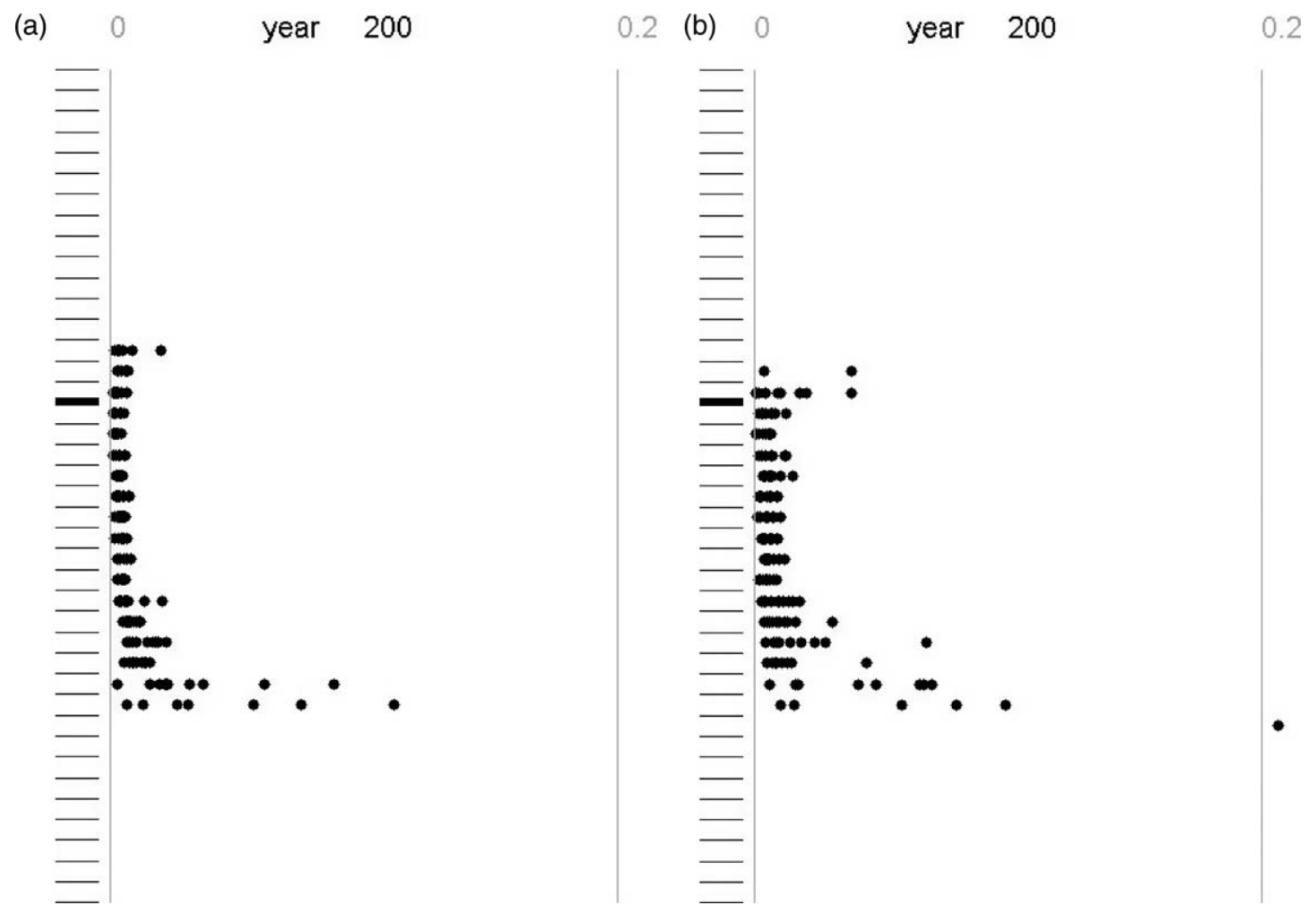

Figure 6. All $\mathrm{F}_{\mathrm{ST}}$ values in each $50 \mathrm{~km}$ range (displayed as the horizontal lines) during the movement of the temperature optimum (bold horizontal line) northwards at $4 \mathrm{~km} \mathrm{yr}^{-1}$ in time slice year 200, under weather variabilities 0 (a) and 280 (b). Missing values (i.e. $<10$ $\mathrm{F}_{\mathrm{ST}}$ values noted per range) are the result of simulations leading to 0 individuals in this range.

One would expect that the loss of neutral genetic diversity is aggravated under decreased population connectivity. However, we used model parameters for the species and for the landscape that together produced a wellconnected metapopulation, with $\mathrm{F}_{\mathrm{ST}}$ values calculated for the whole stationary metapopulation ranging from 0.0475 to 0.0868 under average weather variability. Thus there is no reason to assume that limited population connectivity was causing the loss of neutral genetic diversity we observed. We did find an increased number of instances of higher genetic differentiation between populations near range margins (as shown by Eckert et al. 2008). This was probably related to the smaller average population sizes in these margins. However, even in marginal regions $F_{S T}$ values only occasionally went up to 0.2 , and decreased again when population sizes increased in the newly colonised areas. Thus in our model colonisation had no long-term effect on genetic differentiation among patches. This pattern was observed for all temperature increase scenarios.

The landscapes we used in our model were $15 \times 2000$ $\mathrm{km}$. One may expect that the loss of neutral genetic diversity is more pronounced in linear habitats where dispersal follows a stepping stone model. However, in our landscapes the east and west side were merged to diminish edge effects, which in theory leads to an infinitely wide landscape. In metapopulation simulations this is fairly common practice, Johst et al. (2002). With 3000 patches of $400 \mathrm{~m}$ radii, there were always several locations available for dispersing individuals directly north of the northern metapopulation edge. The cylindric structure of the landscape does increase population connectivity compared to what can be expected in a wider, flat, or real-life landscape with the same properties, as individuals can reach a new habitat patch along different routes in east-west direction (Hovestadt and Poethke 2005). This may contribute to the low $\mathrm{F}_{\mathrm{ST}}$ values that we found. However, Beaumont and Nichols (1996) also performed their simulations on a torus while studying effects on $\mathrm{F}_{\mathrm{ST}}$ values. Besides, this effect was small compared to the benefit of avoiding edge effects. In addition, it contributed to a less stochastic behavior of the colonisation process at the leading edge, which simplified the interpretation of the results. Real species distribution areas will often contain stretches in which suitable habitat is confined to a few patches in a narrow corridor, and such bottlenecks can be expected to lead to an even more pronounced loss of neutral genetic diversity under range shifts than we have shown here under unconstrained dispersal.

We used current climate change scenarios $\left(2\right.$ and $4{ }^{\circ} \mathrm{C}$ warming by 2100) and projected them over the next $600 \mathrm{yr}$. It is unlikely that current projections will be valid for such a long time period. It is relevant, however, that if we would be able to stop temperature increase by for example 2100 , the modelled metapopulations will not yet have gone extinct under both temperature increase scenarios, and they will still contain most of their genetic diversity in the surviving southern original parts of their ranges.

\section{The effects of increased weather variability on neutral genetic diversity under range shifts}

We found that neutral genetic diversity was always lowest under high weather variability, independent of population 
sizes. Under high weather variability, population sizes at climate optimum did not reach carrying capacity. As a result genetic drift in these populations increased compared to scenarios with lower weather variabilities, leading to lowered levels of neutral genetic diversity in these populations and thus overall in the metapopulation. Although differences between weather variability scenarios were small and arguably negligible compared to the effects of temperature increase, we did see that these initial differences in neutral genetic diversity were maintained throughout the time series. The effect of weather variability on level of neutral genetic diversity was therefore small yet persistent. There was also a small increase in the occurrence of higher genetic differentiation between populations throughout the metapopulation under increased weather variability, probably also the result of an increase in genetic drift.

In our study the simulated weather variability was already implemented during the burn-in phase of the model run, and we did not study the effect of an increase in weather variability at the start of the climate change scenarios. However, the differences between the average weather variability and the two extreme values of no and twice as much weather variability were so much smaller than the temperature change effects that they probably would have gone unnoticed if they had occurred together.

\section{Perspectives}

Until now, weather variability has not often been taken into account separately in climate change studies (but see e.g. Verboom et al. 2010, Schippers et al. 2011). Verboom et al. (2010) concluded that increased weather variability can have important consequences for species' conservation programmes. Our results may be taken to suggest that the effect of weather variability is small with regard to the loss of genetic diversity caused by temperature change. However, as in our model the climate suitability follows a stable, yet moving, curve throughout the simulated time series, the random effects on temperature optimum are always spatially correlated: if temperature is not optimal at a given location in a certain year, there will be always be optimal conditions further to the north or to the south. So there is never a threat to the whole metapopulation simultaneously. This is not representative of extreme weather events such as the hot summer of 2003, when there were very high temperatures all over Europe. It would thus be interesting to study the effects of weather variability on population sizes and genetic diversity in metapopulations more thoroughly and with methods different from ours.

Our model did not include rare long distance dispersal, which might support metapopulation survival or improve migration under climate change. However, in contrast to plants, our model species requires a mate to reproduce, and this could seriously hamper successful colonization by the occasional long distance migrating bird. Furthermore, rare long distance dispersal that is successful would likely aggravate the founder effects shown in this study.

Another contribution to survival beyond our model predictions could come from selection and adaptation to changing conditions, rather than (or combined with) merely following the conditions that are currently optimal.
Outbreeding, long-lived species such as trees maintain most of the genetic variation within a population (Austerlitz et al. 2000), and selection takes place every generation (Savolainen et al. 2007). Whether bird species in fragmented landcapes may be able to do the same is unclear. However, if adaptation occurs, it may be at the expense of part of the genetic diversity, which is selected against or lost together with increased selection.

In small patches with low genetic diversity, inbreeding may have an adverse effect on population demography, through e.g. a decreased number of offspring, in species that are sensitive for inbreeding. We did not include inbreeding in our model, as we were interested in demographic effects only. Besides, we modelled a medium disperser in a reasonably connected landscape. In such a landscape inbreeding can be effectively avoided by dispersal (Szulkin and Sheldon 2008).

Current biodiversity monitoring systems usually assess the number of individuals at regular intervals, and the IUCN red lists of endangered species categories are based on assessments of population sizes, the level of fragmentation and the span of occurrence, in combination with species traits. Our results, supported by earlier empirical studies (Hewitt 1996, Neve et al. 2009), indicate that these biodiversity monitoring tools may not accurately reflect the trend in level of species' genetic diversity. Laikre et al. (2010) state that currently used indicators focusing on genetic diversity only deal with breeds used for food production. Laikre et al. (2008) suggested starting points for a genetic diversity monitoring program, but they did not take effects of climate change into account in their study.

From this and previous studies it can be concluded that species experiencing climate-induced range shifts may be prone to loss of genetic diversity. More research is needed to develop good indicators of monitoring genetic diversity in species subject to climate change-induced range shifts and, more importantly, to develop conservation programmes and management tools to prevent such losses (Smulders et al. 2009). However, initially most of the genetic diversity may still be available in populations in the original species range centre. Our results indicate the importance of conserving such areas as modern refugia of genetic diversity, as argued earlier by Hampe and Petit (2005).

Acknowledgements - We thank Thorsten Wiegand and an anonymous reviewer for valuable comments on an earlier version of this manuscript. This research was supported by the Netherlands' Ministry of Agriculture, Nature Conservation and Food Quality through its strategic research program: 'Sustainable spatial development of ecosystems, landscapes, seas and regions' (projects KB-01-007-001-PRI and KB-01-007-013-PRI) and by the Dutch National Research Programme Climate changes Spatial Planning (<www.klimaatvoorruimte.nl/>) as project A2.4.

\section{References}

Austerlitz, F. et al. 1997. Evolution of coalescence times, genetic diversity and structure during colonization. - Theor. Popul. Biol. 51: 148-164. 
Austerlitz, F. et al. 2000. Effects of colonization processes on genetic diversity: differences between annual plants and tree species. - Genetics 154: 1309-1321.

Beaumont, M. A. and Nichols, R. A. 1996. Evaluating loci for use in the genetic analysis of population structure. - Proc. R. Soc. B 263: 1619-1626.

Besold, J. et al. 2008. Strong genetic impoverishment from the centre of distribution in southern Europe to peripheral Baltic and isolated Scandinavian populations of the pearly heath butterfly. - J. Biogeogr. 35: 2090-2101.

Boileau, M. G. et al. 1992. Nonequilibrium gene-frequency divergence - persistent founder effects in natural populations. - J. Evol. Biol. 5: 25-39.

Bruggeman, D. J. et al. 2010. The relative effects of habitat loss and fragmentation on population genetic variation in the redcockaded woodpecker (Picoides borealis). - Mol. Ecol. 19: 3679-3691.

Eckert, C. G. et al. 2008. Genetic variation across species' geographical ranges: the central-marginal hypothesis and beyond. - Mol. Ecol. 17: 1170-1188.

Edmonds, C. A. et al. 2004. Mutations arising in the wave front of an expanding population. - Proc. Natl Acad. Sci. USA 101: 975-979.

Ewens, W. J. 1972. Sampling theory of selectively neutral alleles. - Theor. Popul. Biol. 3: 87-112.

Excoffier, L. and Ray, N. 2008. Surfing during population expansions promotes genetic revolutions and structuration. - Trends Ecol. Evol. 23: 347-351.

Excoffier, L. et al. 2009. Genetic consequences of range expansions. - Annu. Rev. Ecol. Evol. Syst. 40: 481-501.

Foden, W. et al. 2008. Species susceptibility to climate change impacts. - In: Vié, J.-C. et al. (eds), The 2008 review of the IUCN Red List of threatened species. IUCN Gland, Switzerland.

Frankham, R. et al. 2005. Introduction to conservation genetics. - Cambridge Univ. Press.

Hadley Centre 2003. Climate change. Observations and predictions. - Hadley Centre.

Hagemeijer, W. J. M. and Blair, M. J. 1997. The EBCC atlas of European breeding birds. - T. and A. D. Poyser.

Hampe, A. and Petit, R. J. 2005. Conserving biodiversity under climate change: the rear edge matters. - Ecol. Lett. 8: 461467.

Hewitt, G. M. 1996. Some genetic consequences of ice ages, and their role in divergence and speciation. - Biol. J. Linn. Soc. 58: 247-276.

Hewitt, G. M. and Nichols, R. A. 2005. Genetic and evolutionary impacts of climate change. - In: Lovejoy, T. E. and Hannah, L. (eds), Climate change and biodiversity. Yale Univ. Press, pp. 176-192.

Hovestadt, T. and Poethke, H. J. 2005. Dispersal and establishment: spatial patterns and species-area relationships. - Divers. Distrib. 11: 333-340.

IPCC 2007. Climate change 2007: synthesis report. - In: Fourth Assessment Report of the Intergovernmental Panel on Climate Change, p. 104.

Johst, K. et al. 2002. Metapopulation persistence in dynamic landscapes: the role of dispersal distance. - Oikos 98: 263270.

Klopfstein, S. et al. 2006. The fate of mutations surfing on the wave of a range expansion. - Mol. Biol. Evol. 23: 482-490.

Kosenko, S. M. and Kaigorodova, E. Y. 2001. Effect of habitat fragmentation on distribution, density and breeding performance of the middle spotted woodpecker Dendrocopos medius (Aves, Picidae) in Nerussa-Desna Polesye - Zool. Zhurnal 80: 71-78, in Russian.

Kosinski, Z. and Ksit, P. 2006. Comparative reproductive biology of middle spotted woodpeckers Dendrocopos medius and great spotted woodpeckers D. major in a riverine forest. - Bird Study 53: 237-246.

Kosinski, Z. et al. 2004. Accuracy and efficiency of different techniques for censusing territorial middle spotted woodpeckers Dendrocopos medius. - Acta Ornithol. 39: 29-34.

Laikre, L. et al. 2008. Potentials for monitoring gene level biodiversity: using Sweden as an example. - Biodivers. Conserv. 17: 893-910.

Laikre, L. et al. 2010. Neglect of genetic diversity in implementation of the convention on biological diversity. - Conserv. Biol. 24: $86-88$.

Lande, R. 1993. Risks of population extinction from demographic and environmental stochasticity and random catastrophes. - Am. Nat. 142: 911-927.

Leigh, E. G. 1981. The average lifetime of a population in a varying environment. - J. Theor. Biol. 90: 213-239.

McInerny, G. J. et al. 2009. How range shifts induced by climate change affect neutral evolution. - Proc. R. Soc. B 276: 15271534.

Michalek, K. G. and Winkler, H. 2001. Parental care and parentage in monogamous great spotted woodpeckers (Picoides major) and middle spotted woodpeckers (Picoides medius). - Behaviour 138: 1259-1285.

Nei, M. et al. 1975. Bottleneck effect and genetic variability in populations. - Evolution 29: 1-10.

Neve, G. et al. 2009. Loss of genetic diversity through spontaneous colonization in the bog fritillary butterfly, Proclossiana eunomia (Lepidoptera: Nymphalidae) in the Czech Republic. - Eur. J. Entomol. 106: 11-19.

Opdam, P. and Wascher, D. 2004. Climate change meets habitat fragmentation: linking landscape and biogeographical scale levels in research and conservation. - Biol. Conserv. 117: 285297.

Parmesan, C. 2006. Ecological and evolutionary responses to recent climate change. - Annu. Rev. Ecol. Evol. Syst. 37: 637669.

Parmesan, C. and Yohe, G. 2003. A globally coherent fingerprint of climate change impacts across natural systems. - Nature 421: 37-42.

Pasinelli, G. 2000. Oaks (Quercus sp.) and only oaks? Relations between habitat structure and home range size of the middle spotted woodpecker (Dendrocopos medius). - Biol. Conserv. 93: 227-235.

Pettersson, B. 1985a. Relative importance of habitat area, isolation and quality for the occurrence of middle spotted woodpecker Dendrocopos medius (L) in Sweden. - Holarct. Ecol. 8: 53-58.

Pettersson, B. 1985b. Extinction of an isolated population of the middle spotted woodpecker Dendrocopos medius (L) in Sweden and its relation to general theories on extinction. - Biol. Conserv. 32: 335-353.

Root, T. L. et al. 2003. Fingerprints of global warming on wild animals and plants. - Nature 421: 57-60.

Rousset, F. 2008. GENEPOP’ 007: a complete re-implementation of the GENEPOP software for Windows and Linux. - Mol. Ecol. Resour. 8: 103-106.

Saether, B. E. et al. 1998. Environmental stochasticity and extinction risk in a population of a small songbird, the great tit. - Am. Nat. 151: 441-450.

Savolainen, O. et al. 2007. Gene flow and local adaptation in trees. - Annu. Rev. Ecol. Evol. Syst. 38: 595-619.

Schippers, P. et al. 2011. Metapopulation shift and survival of woodland birds under climate change: will species be able to track. - Ecography doi: 10.1111/j.1600-0587.2011.06712.x.

Scoble, J. and Lowe, A. J. 2010. A case for incorporating phylogeography and landscape genetics into species distribution modelling approaches to improve climate adaptation and conservation planning. - Divers. Distrib. 16: 343-353. 
Settele, J. et al. 2008. Climate risk atlas of European butterflies. - Pensoft Publ.

Smulders, M. J. M. et al. 2009. Landscape genetics of fragmented forests: anticipating climate change by facilitating migration. - iForest 2: 128-132.

Szulkin, M. and Sheldon, B. C. 2008. Dispersal as a means of inbreeding avoidance in a wild bird population. - Proc. R. Soc. B 275: 703-711.

Travis, J. M. J. 2003. Climate change and habitat destruction: a deadly anthropogenic cocktail. - Proc. R. Soc. B 270: 467473.

Travis, J. M. J. et al. 2007. Deleterious mutations can surf to high densities on the wave front of an expanding population. - Mol. Biol. Evol. 24: 2334-2343.

Verboom, J. et al. 2001. Introducing the key patch approach for habitat networks with persistent populations: an example for marshland birds. - Biol. Conserv. 100: 89-101.

Supplementary material (Appendix E6713 at <www.oikos office.lu.se/appendix $>$. Appendix 1-3.
Verboom, J. et al. 2010. Population dynamics under increasing environmental variability: implications of climate change for ecological network design criteria. - Landscape Ecol. 25: 1289-1298.

Vos, C. C. et al. 2001. Toward ecologically scaled landscape indices. - Am. Nat. 157: 24-41.

Vos, C. C. et al. 2008. Adapting landscapes to climate change: examples of climate-proof ecosystem networks and priority adaptation zones. - J. Appl. Ecol. 45: 1722-1731.

Warren, M. S. et al. 2001. Rapid responses of British butterflies to opposing forces of climate and habitat change. - Nature 414: 65-69.

Whittaker, J. C. et al. 2003. Likelihood-based estimation of microsatellite mutation rates. - Genetics 164: 781-787. 